\title{
Trends in the Prevalence of Severe Obesity among Tehranian Adults: Tehran Lipid and Glucose Study, 1999-2017
}

Pouria Mousapour, MD'; Majid Valizadeh, MD'; Maryam Mahdavi'; Navid Saadat, MD²; Maryam Barzin, MD, PhD ${ }^{1 *}$; Fereidoun Azizi, MD²; Farhad Hosseinpanah, MD'

${ }^{1}$ Obesity Research Center, Research Institute for Endocrine Sciences, Shahid Beheshti University of Medical Sciences, Tehran, Iran 2Endocrine Research Center, Research Institute for Endocrine Sciences, Shahid Beheshti University of Medical Sciences, Tehran, Iran

\begin{abstract}
Background: A rise in the global prevalence of severe obesity (body mass index; BMI of $\geq 35 \mathrm{~kg} / \mathrm{m}^{2}$ ) has been reported. In this study, we investigated the trends in the prevalence of severe obesity among Tehranian adults over the past two decades.

Methods: A representative sample of 10,045 Tehranians aged $\geq 19$ years were followed from 1999 to 2017. The trends in the prevalence of severe obesity were investigated over six cross-sectional phases with 3.6-year intervals using generalized estimating equations.

Results: In this cohort, the overall prevalence of severe obesity increased from $4.6 \%$ ( $1.8 \%$ in males and $6.7 \%$ in females) in 1999 to $10.1 \%$ (4.7\% in males and $14.3 \%$ in females) in 2017 . The persisted rising in prevalence in the youngest age-group in both genders, with the most rapid increase among females aged 19-29 years, plateaued in the older ages and remained unchanged among males aged over 50 years. After age-sex standardized analysis by using Tehranian urban population data, the prevalence rates of severe obesity in Tehranian men and women were estimated to be $1.9 \%$ and $5.7 \%$ in 1996 , and $4.5 \%$ and $10.9 \%$ in 2016 , respectively. Conclusion: There was a significant and continuous increase in the prevalence of severe obesity in Tehranian adults over the past two decades. Preventive interventions should be focused on the younger and middle-aged population, to mitigate the subsequent burden of severe obesity on Tehranian population and the healthcare system.

Keywords: Adult, Body mass index, Obesity, Prevalence, Trends

Cite this article as: Mousapour P, Valizadeh M, Mahdavi M, Saadat N, Barzin M, Azizi F, et al. Trends in the prevalence of severe obesity among Tehranian adults: Tehran Lipid and Glucose Study, 1999-2017. Arch Iran Med. 2020;23(6):378-385. doi: 10.34172/ aim.2020.30.
\end{abstract}

Received: July 7, 2019, Accepted: January 5, 2020, ePublished: June 1, 2020

\section{Introduction}

Obesity, the state of excessive accumulation of adipose tissue, is an independent risk factor for a broad spectrum of non-communicable diseases such as diabetes, atherosclerosis and specific types of cancers, and a leading but preventable cause of reduced quality of life and life expectancy. ${ }^{1}$ Severe obesity, defined as body mass index $(\mathrm{BMI}) \geq 35 \mathrm{~kg} / \mathrm{m}^{2}$, has emerged as a major public health concern, affecting $2.3 \%$ of men and $5.0 \%$ of women, worldwide. ${ }^{2}$ Compared to lower BMI categories, individuals with severe obesity are disproportionately predisposed to higher risks of cardiovascular diseases, cancer and all-cause mortality, ${ }^{3,4}$ and place greater costs on the society and healthcare system.,

The worldwide prevalence of severe obesity has dramatically increased during the past several decades; with the same trends, it is forecasted to increase to over $6 \%$ among men and $9 \%$ among women worldwide by 2025. Although the trends of severe obesity have plateaued in most parts of Europe, its prevalence has elevated considerably in Africa and the Middle East as well as high- income English-speaking countries. ${ }^{2}$ A meta-analysis of national and sub-national data suggests that the prevalence of adult with BMI $\geq 30 \mathrm{~kg} / \mathrm{m}^{2}$ in Iran has increased from 2005 to $2014^{7}$; however, the trends of severe obesity remained unclear in that study.

Tehran is the most populous city in Western Asia, and has the second largest metropolitan area in the Middle East, with a high proportion of young adults. The Tehran Lipid and Glucose Study (TLGS) is a longitudinal cohort, launched in 1999 with the objective of determining the prevalence of non-communicable diseases and assessment of cardiometabolic risk factors, among a representative sample of the overall Tehranian residents. Our previous investigation in the framework of TLGS implied rising trends of severe obesity among Tehranian male and female adults from 1999 up to to $2011^{8}$; thus, considering the need for eluciation of these trends over the most recent decade, we designed this study to explore the updated trends of severe obesity among Tehranian adult population and within demographic subgroups from 1999 to 2017. 


\section{Material and Methods}

Study Population

Data came from the TLGS datasets. Detailed description of the TLGS is available elsewhere. ${ }^{9}$ In brief, 15005 and an additional 3555 participants were selected by multistage cluster random sampling methods, in phase I (1999 to 2001) and phase II (2002-2005), respectively. Data from the interviews and anthropometric measurements were recorded and collected by qualified physicians in charge in phases I and II, and then repeatedly in four subsequent phases with approximately 3.6-year intervals: phase III (2006 to 2008), phase IV (2009 to 2011), phase V (2012 to 2014), and phase VI (2015 to 2017). For the current study, we included 10448 individuals aged 19 years or above with available data for the baseline and at least one other phase, and excluded 52 subjects with malignancies, 248 subjects on systemic corticosteroid therapy and 103 pregnant women, at any phase, finally yielding 10045 subjects eligible for the analysis.

\section{Measurements and Definitions}

Baseline information on age, sex, educational level, smoking and marital status were gathered through interviews using standard pretested questionnaires, and the study participants were stratified according to their baseline characteristics. Based on age, the participants were grouped as 19-29, 30-39, 40-49, 50-59 and $\geq 60$ years. Educational level was categorized as: 1) having 12 years of education or less (being illiterate, primary school level, secondary school level or achieving the high school diploma); or 2) with more than 12 years of education (university level). Smoking status was categorized into three subgroups: 'current smokers' defined as those who used any tobacco products (cigarette, pipe, or water pipe) at the time of examination, 'quitters' were those who used to smoke but had quit, and 'never smoked'. Information on leisure-time physical activity (LTPA) was collected using the Persian-translated forms of the Modifiable Activity Questionnaire (MAQ). ${ }^{9}$ LTPA was categorized as: Light, with $\mathrm{MET}<600 \mathrm{~min} / \mathrm{wk}$, and moderate to vigorous, with MET $\geq 600 \mathrm{~min} / \mathrm{wk} .{ }^{10}$ Male and female participants were separately subdivided for marital status as 'married' or 'unmarried' (including never-married, widowed and divorced). Weight was measured while participants were minimally clothed and barefoot, using digital scales (Seca, Hamburg, Germany; range $0.1-150 \mathrm{~kg}$, with an accuracy of up to $100 \mathrm{~g}$ ). Height was measured while barefoot and standing, using a stadiometer, with an accuracy of $1 \mathrm{~mm}$. BMI was calculated as weight in kilograms $(\mathrm{kg})$ divided by height in square meters $\left(\mathrm{m}^{2}\right)$. Severe obesity was defined as BMI $\geq 35 \mathrm{~kg} / \mathrm{m}^{2}$.

\section{Statistical Analysis}

Statistical evaluation was carried out using the SPSS 24.0 software (SPSS, Chicago, IL, USA). For the analysis, cross-sectional data were linked across the study phases. Longitudinal differences in the prevalence of severe obesity according to demographic subgroups at the study baseline, including age, gender, LTPA, educational level, smoking and marital status, were analyzed using the generalized estimated equation (GEE) methods, with autoregressive working correlation structures, through logit link function with binomial errors to investigate the trends in the prevalence. $P$ values were calculated in separate models, for alteration of prevalence over the follow-up period $(P$ trend $)$, general subgroup differences in prevalence $\left(P_{\text {between }}\right.$ groups $)$, and interaction tests between the subgroups ( $P$ interaction $)$; and a $P$ value of $<0.05$ was considered statistically significant. Prevalence odds ratios (PORs) with 95\% confidence intervals were computed in each phase in baseline demographic subgroups, according to the GEE models, considering severe obesity as response. We finally provided age-sex standardized prevalence of severe obesity in phases I and II based on the 2005 census, phases III and IV based on the 2010 census, and V and VI based on the 2011 census of the Tehranian urban population ${ }^{11}$.

\section{Results}

A total of 10045 participants (44.6\% male) were included. Baseline population demographics are presented in Table 1. The mean age of participants was $40.9 \pm 14.4$ years and mean BMI was $26.6 \pm 4.7 \mathrm{~kg} / \mathrm{m}^{2}\left(25.8 \pm 4.1 \mathrm{~kg} / \mathrm{m}^{2}\right.$ in men and $27.3 \pm 5 \mathrm{~kg} / \mathrm{m}^{2}$ in women). The baseline prevalence of severe obesity was $4.5 \%$, and it was significantly higher

Table 1. Study Population Baseline Characteristics

\begin{tabular}{|c|c|c|c|c|}
\hline Characteristics & Total & Male $(n=4480)$ & Female $(n=5565)$ & $P$ Value \\
\hline Age $(y)$, mean $\pm S D$ & $40.9 \pm 14.4$ & $42.2 \pm 15.1$ & $39.8 \pm 13.8$ & $<0.001$ \\
\hline $\mathrm{BMI}\left(\mathrm{kg} / \mathrm{m}^{2}\right)$, mean $\pm \mathrm{SD}$ & $26.6 \pm 4.7$ & $25.8 \pm 4.1$ & $27.3 \pm 5$ & $<0.001$ \\
\hline Severe obesity*, No. (\%) & $440(4.5)$ & 85 (1.9) & $355(6.5)$ & $<0.001$ \\
\hline Low LTPA, No. (\%) & $6648(68.5)$ & 3009 (69.8) & $3639(67.5)$ & 0.015 \\
\hline Education $\leq 12$ years, No. (\%) & $8557(86.5)$ & $3636(82.2)$ & $4921(89.9)$ & $<0.001$ \\
\hline Current smoker, No. (\%) & $1319(13.5)$ & $1161(26.8)$ & $158(2.9)$ & $<0.001$ \\
\hline Quitter, No. (\%) & $738(7.6)$ & $654(15.1)$ & $84(1.6)$ & $<0.001$ \\
\hline Married, No. (\%) & $8478(84.4)$ & $3626(81.0)$ & $4852(87.2)$ & $<0.001$ \\
\hline
\end{tabular}

BMI, body mass index; LTPA, leisure-time physical activity.

*Severe obesity was defined as $\mathrm{BMI} \geq 35 \mathrm{~kg} / \mathrm{m}^{2}$. 
among women (1.9\% in men and $6.5 \%$ in women).

The results of the GEE analysis are illustrated in Table 2 and Table S1. In TLGS, the prevalence of severe obesity consistently increased from 1999 to 2017 in both genders, and remained significantly higher in women over the follow-up period $\left(P_{\text {trend }}\right.$ (male and female $)<0.001, P_{\text {between }}$ groups $<0.001$ and $\left.P_{\text {interaction }}=0.564\right)$. The total prevalence of severe obesity in men and women increased from $1.8 \%$ and $6.7 \%$ at the study baseline, to $4.7 \%$ and $14.3 \%$ at the end of the follow-up, respectively. During follow-up, the prevalence of severe obesity increased in all women and in men aged 19-29, 30-39 and 40-49 years, but it plateaued in men aged $50-59$ years $\left(P_{\text {trend }}=0.816\right)$ and $\geq 60$ years $\left(P_{\text {trend }}=0.525\right)$. The prevalence of severe obesity was comparable at baseline between the two genders of $19-29$ years age-groups ( $2 \%$ in men and $1.5 \%$ in women) which reached $5.4 \%$ in men and $9.2 \%$ in women at the end of the follow-up period $\left(P_{\text {between groups }}=0.733\right)$; but in other age groups, it was significantly higher among women than men in all study phases $\left(P_{\text {between groups }}<0.001\right)$

Table 2. Trends in the Prevalence of Severe Obesity $\left(\mathrm{BMI} \geq 35 \mathrm{~kg} / \mathrm{m}^{2}\right.$ ) among Tehranian Adults According to Baseline Demographic Subgroups (Tehran Lipid and Glucose Study, 1999-2017)

\begin{tabular}{|c|c|c|c|c|c|c|c|c|c|}
\hline & \multicolumn{6}{|c|}{ Phases } & \multirow{2}{*}{$\boldsymbol{P}_{\text {trend }}$} & \multirow{2}{*}{$\boldsymbol{P}_{\text {between groups }}$} & \multirow[b]{2}{*}{$\boldsymbol{P}_{\text {interaction }}$} \\
\hline & I & II & III & IV & V & VI & & & \\
\hline Total & 4.6 & 6.3 & 7.5 & 9 & 9.8 & 10.1 & $<0.001$ & \multirow{3}{*}{$<0.001$} & \multirow{3}{*}{0.564} \\
\hline Male & 1.8 & 2.6 & 3.1 & 3.7 & 4.3 & 4.7 & $<0.001$ & & \\
\hline Female & 6.7 & 9.3 & 11 & 13.2 & 14.1 & 14.3 & $<0.001$ & & \\
\hline \multicolumn{10}{|c|}{ Male } \\
\hline \multicolumn{10}{|l|}{ Age group } \\
\hline $19-29$ years & 2.0 & 2.9 & 4.1 & 4.2 & 5.4 & 5.4 & $<0.001$ & \multirow{5}{*}{0.329} & \multirow{5}{*}{0.001} \\
\hline 30-39 years & 1.8 & 2.5 & 3.7 & 5.4 & 5.4 & 6.2 & $<0.001$ & & \\
\hline 40-49 years & 1.2 & 2.6 & 2.8 & 3.0 & 3.7 & 4.7 & $<0.001$ & & \\
\hline $50-59$ years & 2.7 & 3.0 & 2.3 & 2.4 & 3.0 & 2.3 & 0.816 & & \\
\hline$\geq 60$ years & 1.6 & 1.9 & 1.7 & 2.1 & 1.8 & 2.0 & 0.525 & & \\
\hline \multicolumn{10}{|c|}{ Leisure-time physical activity } \\
\hline Low & 1.7 & 2.3 & 2.7 & 3.9 & 4.4 & 5.0 & $<0.001$ & \multirow{2}{*}{$<0.001$} & \multirow{2}{*}{0.010} \\
\hline Moderate to vigorous & 2.5 & 3.0 & 3.8 & 3.3 & 3.9 & 4.2 & 0.001 & & \\
\hline \multicolumn{10}{|l|}{ Education level } \\
\hline$\leq 12$ years & 2.0 & 2.8 & 3.0 & 3.8 & 4.4 & 4.9 & $<0.001$ & \multirow{2}{*}{$<0.001$} & \multirow{2}{*}{0.383} \\
\hline$>12$ years & 1.2 & 1.7 & 3.0 & 3.5 & 3.6 & 4.1 & $<0.001$ & & \\
\hline \multicolumn{10}{|l|}{ Marital status } \\
\hline Married & 1.9 & 2.6 & 2.9 & 3.7 & 4 & 4.5 & $<0.001$ & \multirow{2}{*}{0.507} & \multirow{2}{*}{0.169} \\
\hline Unmarried & 1.6 & 2.3 & 3.6 & 4.0 & 5.3 & 5.6 & $<0.001$ & & \\
\hline \multicolumn{10}{|l|}{ Smoking status } \\
\hline Current Smoker & 1.0 & 2.6 & 3.6 & 3.8 & 3.9 & 4.0 & $<0.001$ & \multirow{3}{*}{$<0.001$} & \multirow{3}{*}{0.440} \\
\hline Quitter & 2.9 & 2.6 & 2.5 & 3.7 & 3.9 & 5.5 & 0.023 & & \\
\hline Never smoked & 2.0 & 2.6 & 2.9 & 3.8 & 4.4 & 4.9 & $<0.001$ & & \\
\hline & & & & Fem & & & & & \\
\hline Age group & & & & & & & & & \\
\hline $19-29$ years & 1.5 & 3.6 & 5.5 & 7.0 & 8.6 & 9.2 & $<0.001$ & & \\
\hline 30-39 years & 5.6 & 8.5 & 10.2 & 12.6 & 14.0 & 14.5 & $<0.001$ & & \\
\hline $40-49$ years & 9.7 & 11.9 & 14.4 & 18.6 & 19.1 & 18.8 & $<0.001$ & $<0.001$ & $<0.001$ \\
\hline 50-59 years & 11.7 & 14.0 & 15.1 & 18.0 & 18.8 & 17.3 & $<0.001$ & & \\
\hline$\geq 60$ years & 8.3 & 10.8 & 11.9 & 12.1 & 10.7 & 12.1 & 0.003 & & \\
\hline Leisure-time physical a & & & & & & & & & \\
\hline Low & 7.5 & 10.9 & 12.7 & 14.5 & 15.2 & 15.2 & $<0.001$ & $<0001$ & 0117 \\
\hline Moderate to vigorous & 4.8 & 6.7 & 7.8 & 11.3 & 12.8 & 12.8 & $<0.001$ & -0.001 & \\
\hline Education level & & & & & & & & & \\
\hline$\leq 12$ years & 7.1 & 10.0 & 11.6 & 14.0 & 15.1 & 15.5 & $<0.001$ & - & 0579 \\
\hline$>12$ years & 2.4 & 3.4 & 5.6 & 7.0 & 7.1 & 4.9 & 0.001 & $<0.001$ & 0.379 \\
\hline Marital status & & & & & & & & & \\
\hline Married & 7.5 & 10.1 & 11.9 & 14.5 & 15.4 & 15.3 & $<0.001$ & 00001 & م \\
\hline Unmarried & 0.9 & 2.2 & 3.8 & 4.0 & 4.9 & 6.6 & $<0.001$ & $<0.001$ & 0.001 \\
\hline Smoking status & & & & & & & & & \\
\hline Current Smoker & 6.2 & 6.7 & 8.0 & 15.4 & 17.3 & 23.9 & $<0.001$ & & \\
\hline Quitter & 7.4 & 6.1 & 7.5 & 14.0 & 13.0 & 12.8 & $<0.001$ & $<0.001$ & 0.271 \\
\hline Never smoked & 6.8 & 9.6 & 11.2 & 13.3 & 14.3 & 14.2 & $<0.001$ & & \\
\hline
\end{tabular}

Values are expressed as percentages of sever obesity. 


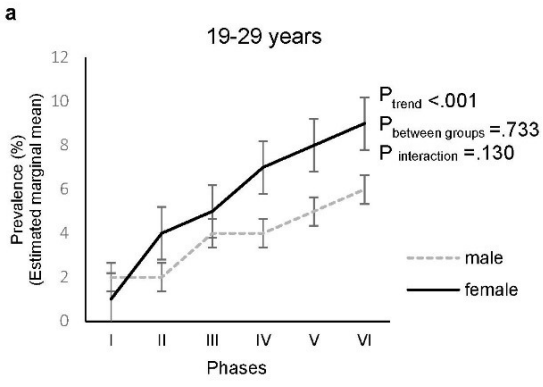

b
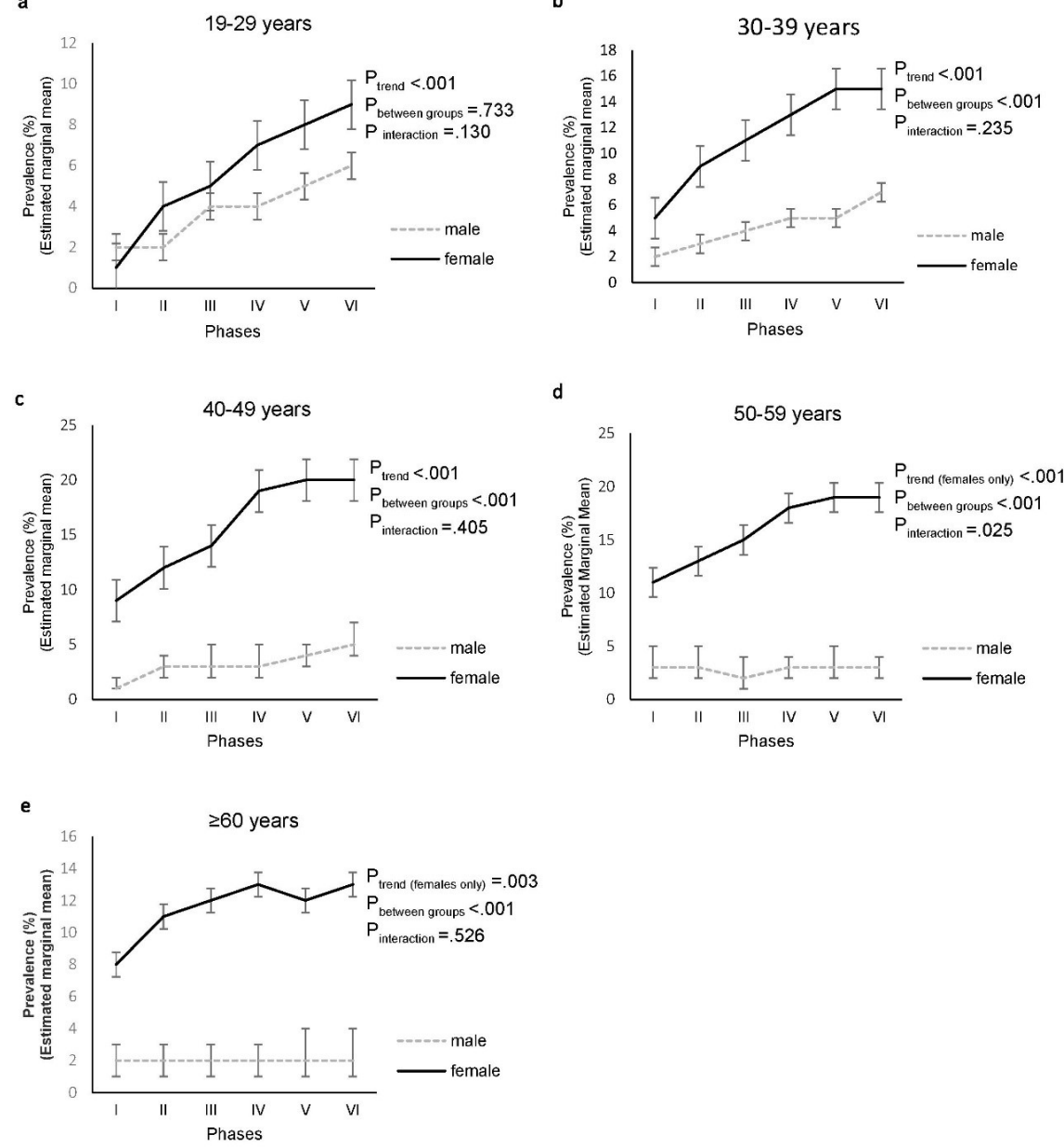

Figure 1. Trends of severe obesity (BMI $\geq 35 \mathrm{~kg} / \mathrm{m}^{2}$ ) among Tehranian adults in baseline age-groups of: a) $19-29$, b) $30-39$, c) 40-49, d) $50-59$ and e) $\geq 60$ years, across the Tehran Lipid and Glucose Study (TLGS) phases. Phase I (1999 to 2001), II (2002 to 2005), III (2006 to 2008), IV (2009 to 2011), V (2012 to 2014) and VI (2015 to 2017).

(Figure 1). After age-sex standardized analysis using the Tehranian urban population data, the prevalence of severe obesity in men and women was $1.9 \%$ and $5.7 \%$ according to the 1996 census, $3.3 \%$ and $8.7 \%$ according to the 2006 census, and $4.5 \%$ and $10.9 \%$ according to the 2016 census, respectively.

The prevalence of severe obesity increased within the subgroups of low and moderate to vigorous LTPA in both genders $\left(P_{\text {trend }}\right.$ (both groups) $\left.<0.001\right)$. Men with moderate to vigorous LTPA showed a higher increase in the prevalence of severe obesity over the follow-up period, compared to those with low LTPA, while the trends were comparable in different LTPA subgroups in women $(P$ $=0.010$ in males and 0.117 in females). In both genders, the prevalence of severe obesity was persistently higher among individuals with baseline education $\leq 12$ years throughout follow-up, compared to those with $>12$ years of education $\left(P_{\text {between groups }}\right.$ (male and female $\left.)<0.001\right)$, while the trends were comparable between both subgroups $\left(P_{\text {interaction }}=0.383\right.$ in males and 0.579 in females $)$. The prevalence of severe obesity increased among all subgroups of marital status in both genders. Married and unmarried men demonstrated no significant differences in the prevalence and trends of severe obesity throughout the follow-up period $\left(P_{\text {between groups }}=0.507, P_{\text {interaction }}=0.169\right)$, while over the follow-up period, the prevalence remained higher among married women, compared to those who were unmarried $\left(P_{\text {between groups }}<0.001\right)$. The trends of severe obesity plateaued among married women, but remained rising among the unmarried $\left(P_{\text {interaction }}=0.001\right)$. The prevalence of severe obesity also increased similarly in all subgroups of smoking status in both genders $\left(P_{\text {interaction }}=\right.$ 0.440 in males and 0.271 in females) (Figure 2).

Tables 3 and 4 provide PORs for the development of severe obesity in different demographic subgroups in each phase among men and women, respectively. In comparison with baseline, PORs for severe obesity in phases II to VI were $1.461 .84,2.15,2.42$ and 2.87 in men, and $1.51,1.81$, $2.37,2.59$ and 2.66 in women, respectively. The PORs of severe obesity increased significantly in women of all ages and in men aged 19-29, 30-39 and 40-49 years at baseline, while men aged 50-59 and $\geq 60$ years demonstrated no significant change in the risk of severe obesity. In both genders, the PORs of severe obesity significantly increased 

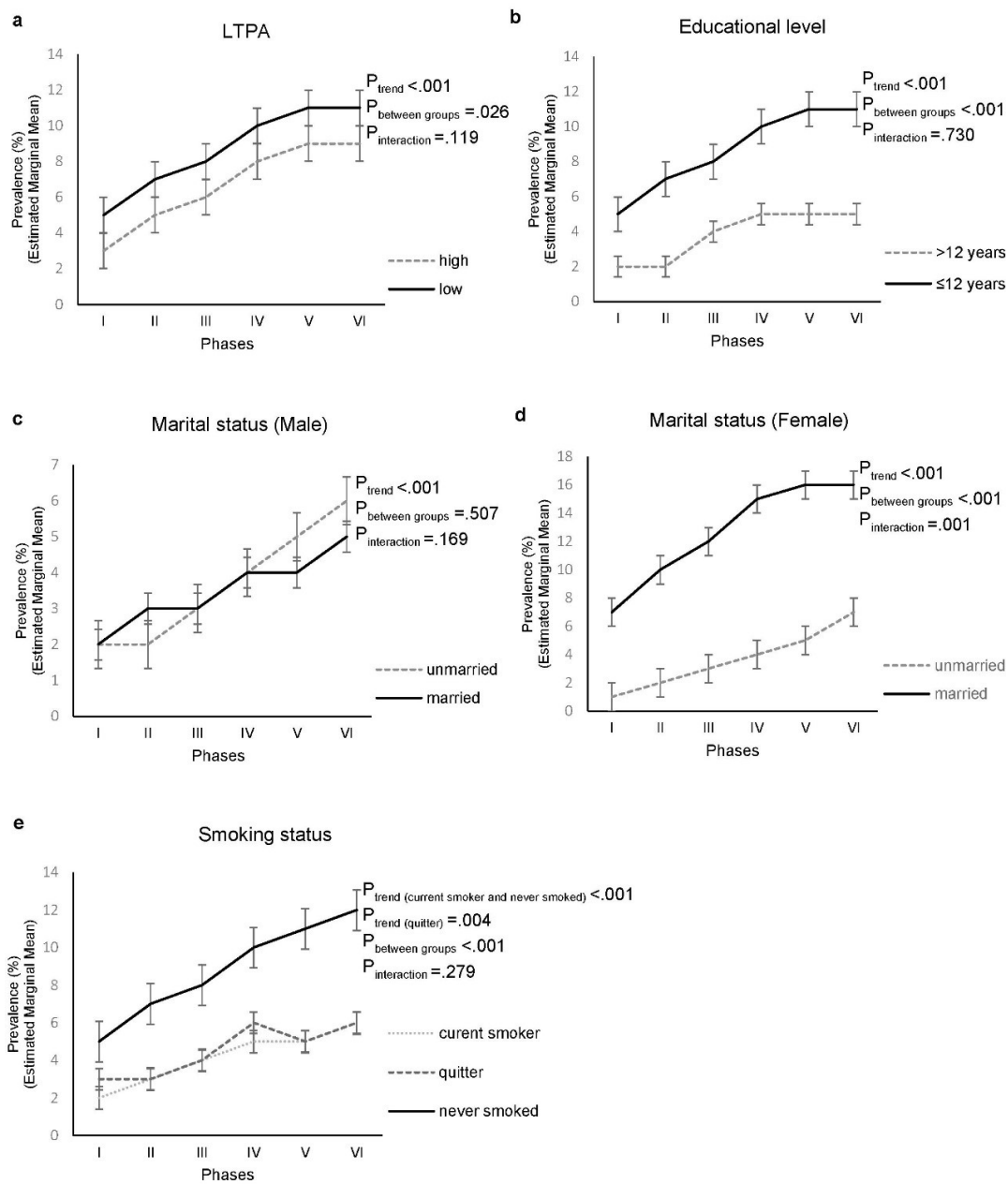

Figure 2. Trends of severe obesity (BMI $\geq 35 \mathrm{~kg} / \mathrm{m}^{2}$ ) among Tehranian adults in baseline demographic subgroups of: a) leisure-time physical activity (LTPA), b) educational level, c) marital status in males, d) marital status in females and e) smoking status, across the Tehran Lipid and Glucose Study (TLGS) phases. Phase I (1999 to 2001), II (2002 to 2005), III (2006 to 2008), IV (2009 to 2011), V (2012 to 2014) and VI (2015 to 2017).

in all subgroups of LTPA, educational level and marital status, and were smaller for married women, compared to women who were unmarried at the study baseline. Moreover, PORs of severe obesity increased in current smokers and quitters in both genders, but did not increase significantly in women who had quit smoking.

\section{Discussion}

In the present study, we found a more than a two-fold rise in the prevalence of severe obesity over two decades of follow-up among TLGS adult male and female participants. Likewise, age-sex standardized analysis based on the Tehranian urban adult population data demonstrated a remarkably high prevalence of severe obesity compared to average global estimates, ${ }^{2}$ which has significantly and continuously increased over the past two decades.

Various trends of adult severe obesity have been reported worldwide. The prevalence of severe obesity in Australian adults increased from $3.6 \%$ and $6.5 \%$ in 1995 to $7.9 \%$ and $11.1 \%$ in 2012 in males and females, respectively. ${ }^{12}$ In Canada, from 2001 to 2011, the national prevalence of severe obesity increased from $3.6 \%$ to $4.6 \%$ in men and from $4.5 \%$ to $5.7 \%$ in women. ${ }^{13}$ Interestingly, a persistently high prevalence of severe obesity has also been reported among US adults aged 20 years or older over one decade since 2003 , which reached $11.9 \%$ in men and $17.1 \%$ in women in 2012. ${ }^{14}$ In a more recent report from 2007 to 2016 in the US, the adult prevalence of BMI $\geq 40 \mathrm{~kg} / \mathrm{m}^{2}$ increased from $4.2 \%$ to $5.6 \%$ in men, and from $7.3 \%$ to $9.7 \%$ in women. ${ }^{15}$ Consistent with our observation, the mentioned studies reported higher prevalence of severe obesity in women than men, suggesting this gender difference to be a consequence of hormonal and biological disparities between the two genders. ${ }^{16}$ On the other hand, we observed that the upward trends of the prevalence of severe obesity plateaued in men aged over 50 years, while persisted to rise in women of the same age. This part of our findings may reflect the influence of menopause, which is associated with increased total body fat volume. ${ }^{16}$

Weight gain is multifactorial and reflects a complex interplay of a constellation of genetic, environmental, socioeconomic and behavioral factors. ${ }^{17,18}$ We observed upward trends in the prevalence of severe obesity in younger age-groups, which plateaued after the 6th decade 
Table 3. Prevalence Odds Ratio (POR) and 95\% Confidence Intervals (Cl) for Severe Obesity (BMI $\left.\geq 35 \mathrm{~kg} / \mathrm{m}^{2}\right)$ in Females According to Baseline Demographic Subgroups (Tehran Lipid and Glucose Study, 1999-2017)

\begin{tabular}{|c|c|c|c|c|c|c|}
\hline & \multicolumn{6}{|c|}{ Phases } \\
\hline & $I$ & II & III & IV & V & VI \\
\hline & POR $(95 \% \mathrm{Cl})$ & POR $(95 \% \mathrm{CI})$ & POR $(95 \% \mathrm{Cl})$ & POR $(95 \% \mathrm{CI})$ & POR $(95 \% \mathrm{CI})$ & POR $(95 \% \mathrm{CI})$ \\
\hline Total & 1 & $1.46(1.19,1.80)$ & $1.84(1.45,2.33)$ & $2.15(1.71,2.72)$ & $2.42(1.90,3.09)$ & $2.87(2.26,3.65)$ \\
\hline \multicolumn{7}{|l|}{ Age (y) } \\
\hline $19-29$ & 1 & $1.38(0.88,2.16)$ & $2.40(1.40,4.09)$ & $2.61(1.57,4.33)$ & $3.28(1.99,5.40)$ & $3.58(2.17,5.92)$ \\
\hline $30-39$ & 1 & $1.68(1.08,2.61)$ & $2.48(1.56,3.92)$ & $3.38(2.12,5.40)$ & $3.41(2.10,5.56)$ & $4.24(2.63,6.84)$ \\
\hline $40-49$ & 1 & $2.07(1.19,3.60)$ & $2.60(1.42,4.80)$ & $2.49(1.33,4.65)$ & $2.88(1.57,5.27)$ & $3.90(2.09,7.29)$ \\
\hline $50-59$ & 1 & $1.04(0.69,1.56)$ & $0.74(0.42,1.29)$ & $0.91(0.55,1.50)$ & $1.05(0.58,1.90)$ & $0.92(0.52,1.63)$ \\
\hline$\geq 60$ & 1 & $1.36(0.84,2.21)$ & $1.16(0.64,2.13)$ & $1.21(0.61,2.42)$ & $1.23(0.55,2.76)$ & $1.36(0.62,3.02)$ \\
\hline \multicolumn{7}{|c|}{ Leisure-time physical activity } \\
\hline Low & 1 & $1.41(1.10-1.81)$ & $1.72(1.29-2.28)$ & $2.39(1.81-3.15)$ & $2.63(1.96-3.53)$ & $3.31(2.48-4.41)$ \\
\hline Moderate to vigorous & 1 & $1.56(1.03-2.36)$ & $2.06(1.29-3.29)$ & $1.72(1.08-2.72)$ & $1.99(1.24-3.20)$ & $2.11(1.32-3.35)$ \\
\hline \multicolumn{7}{|l|}{ Education level } \\
\hline$\leq 12$ years & 1 & $1.48(1.18-1.85)$ & $1.75(1.36-2.25)$ & $2.06(1.61-2.64)$ & $2.38(1.83-3.11)$ & $2.78(2.14-3.61)$ \\
\hline$>12$ years & 1 & $1.48(0.86-2.54)$ & $2.38(1.20-4.70)$ & $2.83(1.42-5.66)$ & $2.85(1.52-5.35)$ & $3.76(2.00-7.06)$ \\
\hline \multicolumn{7}{|l|}{ Marital status } \\
\hline Married & 1 & $1.49(1.19-1.86)$ & $1.75(1.35-2.28)$ & $2.04(1.58-2.64)$ & $2.25(1.72-2.96)$ & $2.68(2.05-3.49)$ \\
\hline Unmarried & 1 & $1.26(0.74-2.14)$ & $2.22(1.26-3.88)$ & $2.74(1.56-4.80)$ & $3.24(1.87-5.61)$ & $3.80(2.17-6.64)$ \\
\hline \multicolumn{7}{|l|}{ Smoking status } \\
\hline Current Smoker & 1 & $2.34(1.40-3.92)$ & $3.31(1.87-5.86)$ & $3.59(2.00-6.45)$ & $3.78(2.09-6.84)$ & $4.16(2.28-7.58)$ \\
\hline Quitter & 1 & $0.88(0.52-1.47)$ & $1.03(0.59-1.79)$ & $1.33(0.78-2.25)$ & $1.27(0.71-2.28)$ & $1.79(1.01-3.15)$ \\
\hline Never smoked & 1 & $1.50(1.17-1.91)$ & $1.75(1.30-2.35)$ & $2.15(1.61-2.87)$ & $2.48(1.82-3.37)$ & $2.95(2.18-3.98)$ \\
\hline
\end{tabular}

Table 4. Prevalence Odds Ratio (POR) and 95\% Confidence Intervals (Cl) for Severe Obesity (BMI $\geq 35 \mathrm{~kg} / \mathrm{m}^{2}$ ) in Females According to Baseline Demographic Subgroups (Tehran Lipid and Glucose Study, 1999-2017)

\begin{tabular}{|c|c|c|c|c|c|c|}
\hline & \multicolumn{6}{|c|}{ Phases } \\
\hline & I & II & III & IV & V & VI \\
\hline & POR $(95 \% \mathrm{Cl})$ & POR $(95 \% \mathrm{CI})$ & POR $(95 \% \mathrm{CI})$ & POR $(95 \% \mathrm{CI})$ & POR $(95 \% \mathrm{Cl})$ & POR $(95 \% \mathrm{Cl})$ \\
\hline Total & 1 & $1.51(1.36,1.67)$ & $1.81(1.64,2.01)$ & $2.37(2.13,2.65)$ & $2.59(2.31,2.89)$ & $2.66(2.37,2.99)$ \\
\hline \multicolumn{7}{|l|}{ Age $(y)$} \\
\hline $19-29$ & 1 & $2.77(1.76,4.35)$ & $3.71(2.33,5.90)$ & $5.05(3.21,7.95)$ & $6.34(3.98,10.11)$ & $7.12(4.42,11.48)$ \\
\hline $30-39$ & 1 & $1.81(1.46,2.25)$ & $2.17(1.73,2.71)$ & $2.79(2.22,3.50)$ & $3.16(2.51,3.98)$ & $3.20(2.52,4.08)$ \\
\hline $40-49$ & 1 & $1.39(1.15,1.67)$ & $1.69(1.41,2.02)$ & $2.42(1.98,2.95)$ & $2.48(2.02,3.05)$ & $2.53(2.05,3.11)$ \\
\hline $50-59$ & 1 & $1.26(1.05,1.50)$ & $1.45(1.20,1.77)$ & $1.81(1.47,2.23)$ & $1.94(1.58,2.39)$ & $1.87(1.50,2.33)$ \\
\hline$\geq 60$ & 1 & $1.34(1.02,1.75)$ & $1.51(1.15,1.98)$ & $1.70(1.25,2.33)$ & $1.57(1.09,2.26)$ & $1.63(1.08,2.44)$ \\
\hline \multicolumn{7}{|c|}{ Leisure-time physical activity } \\
\hline Low & 1 & $1.50(1.34-1.68)$ & $1.81(1.62-2.03)$ & $2.29(2.03-2.58)$ & $2.45(2.16-2.77)$ & $2.49(2.19-2.84)$ \\
\hline Moderate to vigorous & 1 & $1.56(1.24-1.98)$ & $1.82(1.44-2.29)$ & $2.68(2.09-3.43)$ & $3.03(2.36-3.90)$ & $3.18(2.47-4.09)$ \\
\hline \multicolumn{7}{|l|}{ Education level } \\
\hline$\leq 12$ years & 1 & $1.50(1.35-1.66)$ & 1.77 (1.60-1.97) & $2.32(2.08-2.59)$ & $2.56(2.28-2.86)$ & $2.67(2.37-3.00)$ \\
\hline$>12$ years & 1 & $1.66(0.86-3.19)$ & $2.90(1.55-5.42)$ & $3.83(2.03-7.23)$ & 3.67 (1.92-7.05) & $2.72(1.34-5.52)$ \\
\hline \multicolumn{7}{|l|}{ Marital status } \\
\hline Married & 1 & $1.49(1.34-1.65)$ & $1.78(1.61-1.98)$ & $2.35(2.11-2.63)$ & $2.54(2.27-2.84)$ & $2.56(2.28-2.88)$ \\
\hline Unmarried & 1 & $2.63(1.05-6.60)$ & $3.77(1.59-8.92)$ & $4.46(1.88-10.55)$ & $6.02(2.52-14.38)$ & $8.53(3.50-20.81)$ \\
\hline \multicolumn{7}{|l|}{ Smoking status } \\
\hline Current Smoker & 1 & $1.04(0.72-1.52)$ & $1.34(0.74-2.43)$ & $2.56(1.44-4.53)$ & $2.51(1.37-4.61)$ & $3.95(2.06-7.59)$ \\
\hline Quitter & 1 & $1.01(0.44-2.31)$ & $1.24(0.45-3.40)$ & $3.35(1.46-7.71)$ & $2.29(0.94-5.56)$ & $2.52(0.93-6.80)$ \\
\hline Never smoked & 1 & $1.53(1.37-1.70)$ & $1.82(1.64-2.03)$ & $2.35(2.10-2.63)$ & $2.57(2.29-2.88)$ & $2.60(2.31-2.93)$ \\
\hline
\end{tabular}

of life, suggesting rapid development of an obesogenic environment for young and middle-aged population, which is chiefly affected by the phenomenon of modernization, increasing sedentary behaviors and facilitated access to abundant amounts of unhealthy food resources. ${ }^{19}$

Our results indicated that although the trends of severe obesity increased similarly in different subgroups of educational level, in both genders, the prevalence of severe obesity persisted to be higher among those with education levels below university all over the follow-up period. Similarly, a large study, including two US nationally representative datasets of NHANES, reported lower BMI means among those with a college degree, in comparison with those with a high school degree, and a high school 
degree associated with a lower BMI, compared those with education less than high school. ${ }^{20}$ Chang et al also reported similar patterns regarding the association of education level and the prevalence of severe obesity in Taiwan. ${ }^{21}$

We also found that women who were unmarried at baseline were at a considerable long-term risk of severe obesity. The main explanation behind this observation is that in our study population, the subgroup of unmarried participants comprised a high proportion of younger individuals, while older subjects are more likely to be married. On the other hand, baseline unmarried status could accompany transition into marriage over the following years in both men and women, and the risk of developing severe obesity in the unmarried could be attributed to the influence of marital transition on weight gain. Endorsing this hypothesis, one-decade follow-up in TLGS participants indicated that transition into marriage was associated with increased BMI in both males and females, while a transition out of marriage had no effect on BMI. ${ }^{22}$ Also, in a nationwide Iranian study, obesity rates were higher among both formerly and currently married individuals, in comparison with those who had never married. ${ }^{23}$ Nevertheless, since marital status was not tracked in our study, the findings in this regard should be interpreted with caution.

Finally, we observed that, in both genders, the trends of severe obesity increased among different subgroups of LTPA and smoking status. Without doubt, not taking into account the behavioral changes of the individuals through the long follow-up time is among noticeable shortcomings to our study. In addition, we had lack of information regarding the dose-response effect of the amount of tobacco use on severe obesity risk among both smokers and quitters. ${ }^{24,25}$

This study is the first that reports on the trends of severe obesity in an Iranian population over the most recent decade. We included data from a well-defined populationbased cohort (TLGS), and used the anthropometric data, based on accurate clinical measurements, which enhances the reliability and validity, as compared to selfreported measures. As mentioned above, application of baseline demographic information, without updating for possible changes through the follow-up period was a major limitation to our analysis. Besides, due to the absence of data, we did not take into account some factors like dietary habits and economic inequalities in our study. Finally, although we provided evidence on the trends of severe obesity prevalence among a large representative sample of Tehranian residents, the information provided in this study are not generalizable to the total Iranian adult population.

In summary, we found a more than a two-fold rise in the prevalence of severe obesity among TLGS adult male and female participants from 1999 to 2017. Likewise, age-sex standardized analysis based on the Tehranian urban adult population data demonstrated a significant and continuous increase in the prevalence of severe obesity in Tehranian adults over the past two decades.

Awareness of detrimental trends of severe obesity in younger and middle-aged population can guide public health policy making in Iran to ameliorate the burden of severe obesity and improve services to reduce the risk of developing associated non-communicable diseases and premature death later on. Nationwide studies are warranted to track the effect of this phenomenon and related comorbidities on quality and expectancy of life in the Iranian population.

\section{Authors' Contribution}

PM, FH and MB: Study conception and design. PM: Literature search, interpretation and manuscript preparation. $\mathrm{PM}, \mathrm{MB}$ and MM: Data collection and analysis. MV, NS, FA and FH: Manuscript review, critical appraisal and specialist advice. All authors read and approved the manuscript.

\section{Conflict of Interest Disclosures}

The authors have no conflicts of interest.

\section{Ethical Statement}

All participants provided a written informed consent at the beginning of the study. The protocol of the present study, conducted in accordance with principles of the Declaration of Helsinki, received ethical approval from the National Research Council of the Islamic Republic of Iran (No. 121), and was performed with the approval of the Human Research Review Committee of the Endocrine Research Center, Shahid Beheshti University, Tehran, Iran.

\section{Supplementary Materials}

Supplementary file 1 contains Table S1.

\section{Acknowledgements}

The authors are grateful to the staff and participants in the TLGS study for their important contribution.

\section{References}

1. Forouzanfar $M H$, Afshin A, Alexander $L T$, Anderson $H R$, Bhutta ZA, Biryukov S, et al. Global, regional, and national comparative risk assessment of 79 behavioural, environmental and occupational, and metabolic risks or clusters of risks, 1990-2015: a systematic analysis for the Global Burden of Disease Study 2015. Lancet. 2016;388(10053):1659-724. doi: 10.1016/S0140-6736(16)31679-8.

2. NCD Risk Factor Collaboration (NCD-RisC). Trends in adult body-mass index in 200 countries from 1975 to 2014: a pooled analysis of 1698 population-based measurement studies with 19. 2 million participants. Lancet. 2016;387(10026):1377-96. doi: 10.1016/S0140-6736(16)30054-X.

3. Di Angelantonio E, Bhupathiraju SN, Wormser D, Gao P, Kaptoge S, de Gonzalez AB, et al. Body-mass index and all-cause mortality: individual-participant-data metaanalysis of 239 prospective studies in four continents. Lancet. 2016;388(10046):776-86. doi: 10.1016/S01406736(16)30175-1.

4. Prospective Studies Collaboration, Whitlock G, Lewington S, Sherliker P, Clarke R, Emberson J, et al. Body-mass index and cause-specific mortality in 900000 adults: collaborative analyses of 57 prospective studies. The Lancet. 2009;373(9669):1083-96. doi: 10.1016/S01406736(09)60318-4.

5. Andreyeva T, Sturm R, Ringel JS. Moderate and severe obesity have large differences in health care costs. Obes Res. 2004;12(12):1936-43. doi: 10.1038/oby.2004.243.

6. de Oliveira ML, Santos LMP, da Silva EN. Direct healthcare 
cost of obesity in Brazil: an application of the cost-of-illness method from the perspective of the public health system in 2011. PLoS One. 2015;10(4):e0121160. doi: 10.1371/journal. pone.0121160.

7. Jafari-Adli S, Jouyandeh Z, Qorbani M, Soroush A, Larijani B, Hasani-Ranjbar S. Prevalence of obesity and overweight in adults and children in Iran; a systematic review. J Diabetes Metab Disord. 2014;13(1):121. doi: 10.1186/s40200-0140121-2.

8. Barzin M, Keihani S, Hosseinpanah F, Serahati S, Ghareh S, Azizi F. Rising trends of obesity and abdominal obesity in 10 years of follow-up among Tehranian adults: Tehran Lipid and Glucose Study (TLGS). Public Health Nutr. 2015;18(16):29819. doi: 10.1017/s1368980015000269.

9. Azizi F, Ghanbarian A, Momenan AA, Hadaegh F, Mirmiran P, Hedayati $M$, et al. Prevention of non-communicable disease in a population in nutrition transition: Tehran Lipid and Glucose Study phase II. Trials. 2009;10(1):5. doi: 10.1186/1745-621510-5.

10. International Physical Activity Questionnaire. Guidelines for data processing and analysis of the International Physical Activity Questionnaire (IPAQ) -short and long forms. 2005. Available from: https://www.academia.edu/5346814/ Guidelines_for_Data_Processing_and_Analysis_of_the_ International_Physical_Activity_Questionnaire_IPAQ_Short_ and_Long_Forms_Contents.

11. Statistical Centre of Iran. Population and Housing Censuses. Available from: https://www.amar.org.ir/english/Populationand-Housing-Censuses.

12. Keating C, Backholer K, Gearon E, Stevenson C, Swinburn B, Moodie M, et al. Prevalence of class-I, class-II and classIII obesity in Australian adults between 1995 and 2011-12. Obes Res Clin Pract. 2015;9(6):553-62. doi: 10.1016/j. orcp.2015.02.004.

13. Twells LK, Gregory DM, Reddigan J, Midodzi WK. Current and predicted prevalence of obesity in Canada: a trend analysis. CMAJ open. 2014;2(1):E18. doi: 10.9778/cmajo.20130016.

14. Ogden CL, Carroll MD, Kit BK, Flegal KM. Prevalence of childhood and adult obesity in the United States, 2011-2012. JAMA. 2014;311(8):806-14. doi: 10.1001/jama.2014.732.

15. Hales CM, Fryar CD, Carroll MD, Freedman DS, Ogden CL. Trends in obesity and severe obesity prevalence in US youth and adults by sex and age, 2007-2008 to 2015-2016. JAMA. 2018;319(16):1723-5. doi: 10.1001/jama.2018.3060.

16. Leeners B, Geary N, Tobler PN, Asarian L. Ovarian hormones and obesity. Hum Reprod Update. 2017;23(3):300-21. doi: 10.1093/humupd/dmw045.

17. Bell CG, Walley AJ, Froguel P. The genetics of human obesity. Nat Rev Genet. 2005;6(3):221. doi: 10.1038/nrg1556.

18. Koh-Banerjee P, Chu N-F, Spiegelman D, Rosner B, Colditz G, Willett W, et al. Prospective study of the association of changes in dietary intake, physical activity, alcohol consumption, and smoking with 9-y gain in waist circumference among 16587 US men. Am J Clin Nutr. 2003;78(4):719-27. doi: 10.1093/ ajcn/78.4.719

19. Kapoor S, Anand K. Nutritional transition: a public health challenge in developing countries. J Epidemiol Community Health. 2002;56(11):804-5.doi: 10.1136/jech.56.11.804.

20. Liu SY, Kawachi I, Glymour MM. Education and inequalities in risk scores for coronary heart disease and body mass index: evidence for a population strategy. Epidemiology. 2012;23(5):657-64. doi: 10.1097/EDE.0b013e318261c7cc.

21. Chang $\mathrm{H}-\mathrm{C}$, Yang $\mathrm{H}-\mathrm{C}$, Chang $\mathrm{H}-\mathrm{Y}$, Yeh C-J, Chen $\mathrm{H}-\mathrm{H}$, Huang K-C, et al. Morbid obesity in Taiwan: prevalence, trends, associated social demographics, and lifestyle factors. PloS One. 2017;12(2):e0169577. doi: 10.1371/journal. pone.0169577.

22. Hosseinpour-Niazi S, Mirmiran P, Hosseinpanah F, Fallahghohroudy A, Azizi F. Association of marital status and marital transition with metabolic syndrome: tehran lipid and glucose study. Int J Endocrinol Metab. 2014;12(4):e18980. doi: 10.5812/ijem.18980.

23. Janghorbani $M$, Amini $M$, Rezvanian $H$, GOUYA MM, DELAVARI AR, Alikhani $S$, et al. Association of body mass index and abdominal obesity with marital status in adults. Arch Iran Med. 2008;11(3):274-81. doi: 08113/AIM.008.

24. Chiolero A, Faeh D, Paccaud F, Cornuz J. Consequences of smoking for body weight, body fat distribution, and insulin resistance. Am J Clin Nutr. 2008;87(4):801-9. doi: 10.1093/ ajcn/87.4.801.

25. Courtemanche C, Tchernis R, Ukert B. The effect of smoking on obesity: Evidence from a randomized trial. J Health Econ. 2018;57:31-44. doi: 10.1016/j.jhealeco.2017.10.006. 